\title{
Health-related quality of life and emotional and behavioral difficulties after extreme preterm birth: developmental trajectories
}

Bente Johanne Vederhus, Geir Egil Eide, Gerd Karin Natvig, Trond Markestad, Marit Graue, Thomas Halvorsen

Background: Knowledge of long-term health related outcomes in contemporary populations born extremely preterm (EP) is scarce. We aimed to explore developmental trajectories of health-related quality of life (HRQoL) and behavior from mid-childhood to early adulthood in extremely preterm and term-born individuals. Methods: Subjects born at gestational age $\leq 28$ weeks or with birth weight $\leq 1000$ grams within a region of Norway in 1991-92 and matched term-born control subjects were assessed at 10 and 18 years. HRQoL was measured with the Child Health Questionnaire (CHQ) and behavior with the Child Behavior Checklist (CBCL), using parent assessment at both ages and selfassessment at 18 years. Results: All eligible EP $(n=35)$ and control children participated at 10 years, and $31(89 \%)$ and $29(83 \%)$ at 18 years. At 10 years, the EP born boys were given significantly poorer scores by their parents than term-born controls on most CHQ and $\mathrm{CBCL}$ scales, but the differences were minor at 18 years; i.e. significant improvements had occurred in several CHQ (self-esteem, general health and parental impact-time) and $\mathrm{CBCL}$ (total problem, internalizing and anxious/depressed) scales. For the girls, the differences were smaller at 10 years and remained unchanged by 18 years.

Emotional/behavioral difficulties at 10 years similarly predicted poorer improvement on CHQ-scales for both EP and term-born subjects at 18 years. Self-assessment of HRQoL and behavior at 18 years was similar in the EP and term-born groups on most scales.

Conclusions: HRQoL and behavior improved towards adulthood for EP born boys, while the girls remained relatively similar, and early emotional and behavioral difficulties predicted poorer development in HRQoL through adolescence. These data indicate that gender and a longitudinal perspective should be considered when addressing health and wellbeing after extremely preterm birth. 
2 Bente Johanne Vederhus, ${ }^{1,2,3}$ Geir Egil Eide, ${ }^{2,4}$ Gerd Karin Natvig, ${ }^{2}$ Trond Markestad, ${ }^{1,3}$ Marit

3 Graue, ${ }^{1,5}$ Thomas Halvorsen, ${ }^{1.3}$

\section{AUTHORS AFFILIATION}

5 1. Department of Pediatrics, Haukeland University Hospital, Bergen, Norway

6 2. Department of Global Public Health and Primary Care, University of Bergen, Norway

7 3. Department of Clinical Science, University of Bergen, Norway

8 4. Centre for Clinical Research, Haukeland University Hospital, Bergen, Norway

9 5. Centre for Evidence Based Practice, Bergen University College, Bergen, Norway

10 Corresponding author Bente J. Vederhus bente.vederhus@helse-bergen.no,

11 Department of Pediatrics, Haukeland University Hospital,

12 N-5021 Bergen, Norway

$13 \quad$ Tel +4755 975217

$14 \quad$ Fax +4755975147 
15

\section{Introduction}

Children born extremely preterm (EP) are at increased risk of cognitive and social shortcomings, neurosensory deficiencies, psychiatric disorders, lung problems, and cardiovascular disease (Doyle and Anderson 2010; Hack 2009). While early outcome studies of EP-born survivors focused mainly on those with major impairments, more attention is now being paid to consequences of less severe dysfunctions with high prevalence (Aylward 2005) that may have unfavorable consequences for later health-related quality of life (HRQoL) and social functioning.

The sparse knowledge on functional issues and HRQoL in adults born preterm is largely based on studies of subjects born in the 1970-80s, and the impression is that the majority of those without major disabilities do well and live fairly normal lives (Doyle and Anderson 2010; Hack 2009; Moster and others 2008; Saigal 2013). However, neonatal intensive care went through major changes in the early 1990s, improving survival for the most immature and conceivably also the most vulnerable infants (Doyle and Anderson 2010; Wilson-Costello and others 2005). Thus, in Norway approximately $80 \%$ of all infants born more than 12 weeks preterm in 1999-2000 survived to discharge if resuscitated and admitted to neonatal intensive care (Markestad and others 2005).

Emotional and behavioral problems and reduced HRQoL have been described in children born EP in the 1990s (Berbis and others 2012; Johnson and Wolke 2013; Stahlmann and others 2009), but we do not know to what extent and in what ways such challenges persist to adulthood and how these issues relate to each other. Moreover, it is not known if potentially modifiable traits and characteristics may affect these outcomes, such as perceived self-efficacy. Adolescence is an important period in life, characterized by a pace in growth and development second only to that of infancy. Behavioral patterns established in this period have long-lasting effects on future health and well-being, for better or worse. In a cross-sectional study of 10 year old children born EP in 
1991-92,we found that parent reported HRQoL was reduced in boys but not in girls (Vederhus and others 2010). We know from other studies on HRQoL and behavior of children in general that there are age-and gender-related differences which are particularly striking through puberty (Bongers and others 2003; Michel and others 2009). Therefore our primary aim was to explore gender-related development of HRQoL and emotional and behavioral difficulties through puberty from 10 to 18 years of age in EP and term-born individuals, as reported by their parents.

Secondarily, we addressed these same issues by means of self-reports at 18 years of age, and investigated the significance of perceived self-efficacy and associations between neonatal variables and outcome at age 18 .

\section{Methods}

\section{Design and participants}

A longitudinal cohort comparison design was applied. At first follow-up at 10 years of age in 2001-02, all survivors born at gestational age (GA) $\leq 28$ weeks or with birth-weight $(\mathrm{BW}) \leq 1000$ g in 1991-92 within a defined area of Western Norway Health Authority and cared for at the only neonatal intensive care unit in the region (Haukeland University Hospital) were invited ( $\mathrm{n}=35)$. A matched comparison group was established by inviting the temporally nearest term-born child ( $G A \geq 37$ weeks) of the same gender with BW between 3 and $4 \mathrm{~kg}$ (Norwegian $10^{\text {th }}$ to $90^{\text {th }}$ percentile) for each EP-born participant. If that person declined, the next was approached and so on, until a full 1:1 control group was recruited. A second follow-up was performed at 18 years of age in 2008-09. A standard clinical examination was performed by the same pediatrician (TH) at both ages and the medical history was obtained from parents, or in cases of doubt, from medical 
records. Perinatal characteristics of the group born EP were obtained from medical records (Table S1). Results from the first follow-up have been published (Vederhus and others 2010).

\section{Outcome measures - questionnaires}

Participants and parents completed the questionnaires in private, either at the site of the examination or at home. Socio-demographic data were obtained from validated questionnaires used in population studies in Norway, including questions of bullying, physical activity and interaction with friends (The Nord-Trøndelag Health Study 2012; Wold, Smith, and Aaroe 1994).

\section{The Child Health Questionnaire (CHQ)}

HRQoL was assessed by using the CHQ-questionnaires which are generic instruments designed to measure functional health and well-being of children by parent or self-report (Landgraf and others 1999). The CHQ-scales address physical functioning, limitations in social functioning due to physical, emotional or behavioral constraints, general health, pain, self-esteem, mental health and behavior, impact on the parents in terms of emotional strain and time available for themselves, and significance of the child's health on family activity and cohesion. A recall period of the preceding four weeks is used, except for family cohesion and general health. Each item is scored on a 4-6 point Likert scale, and the items in each sub-scale are summarized and transformed into a scale ranging from 0 (poor) to100 (optimal). A validated Norwegian version was used (Selvaag and others 2001). The parent version (CHQ-PF50) consists of 50 questions within 13 scales and was completed at 10 and 18 years. The child form (CHQ-CF87) consists of 87 questions within 12 scales and was completed by self-assessment at 18 years.

\section{Child Behavior Checklist (CBCL) and Youth Self-Report (YSR)}


Emotional and behavioral difficulties and competencies were measured using validated

Norwegian versions of CBCL (parent) and YSR (self-report) (Achenbach and Rescorla 2001;

Novik 1999). The 1991 CBCL version was completed by the parents at 10 and 18 years, while the 2001 YSR version was completed by the children at 18 years. Based on the preceding 6 months each problem-item is scored on a scale ranging from 0 (not true) to 2 (very true or often true), making a total problem score ranging from 0-236 for the CBCL and 0-210 for the YSR. Two broadband scales are composed from five of the eight derived syndrome scales, the internalizing (withdrawn, somatic complaints, anxious/depressed) and externalizing (delinquent or rulebreaking, aggressive behavior). The competence scales measure the amount and the quality of the child's participation in organized activity, sports and hobbies, connection with friends and family, and school performance. Higher score on each scale means more problems or better competencies.

\section{General Self-Efficacy (GSE)}

GSE denotes the perception of one's capacity to achieve a certain goal. It reflects confidence in being able to cope across a wide range of challenging situations and seems to be important to psychosocial functioning (Schwarzer and others 1997). A validated Norwegian 5-item version of the original 10-item GSE scale was completed at 18 years (Roysamb, Schwarzer, and jer 1999). Responses are rated from 'not at all true' (1) to 'exactly true' (4) and an overall mean value ranging from 1 to 4 is calculated.

\section{Statistical methods}

Multiple linear, binary logistic and ordinal logistic regression analyses were used to analyse continuous, binary and ordinal response variables. The mixed linear and generalized linear regression modules in SPSS were used, taking the matched structure of EP and term-born subjects 
104 (gender and age) and the repeated responses (10 and 18 years) into account. These methods allow

105 for contribution also from pairs with declines. Separate analyses for gender were applied for the

106 CHQ-PF50 and CBCL and as sub-analysis for the YSR. Interaction terms were used to assess

107 differences regarding effects of time by group, and gender by group when appropriate. The

108 regression models with self-reported outcomes were adjusted for gender, GSE, maternal

109 education, mild mental retardation and/or ADHD. Further, the regression models with parent-

110 reported changes from 10 to 18 years in the CHQ-scales as dependent variable and the CBCL

111 total problem score at 10 years as predictor variable were adjusted for gender, CHQ-PF50-scores

112 and maternal education at 10 years, and mild mental retardation and/or ADHD. In the group born

113 EP, backward stepwise linear regression analysis was applied to assess associations between

114 outcomes at 18 years and selected neonatal variables (gender, BW $\leq 10$ percentile, intra-

115 ventricular hemorrhage, days on mechanical ventilation, and steroid treatment for

116 bronchopulmonary dysplasia). The parent-reported gender-related trajectories of CHQ-PF50 and

$117 \mathrm{CBCL}$ were also graphically displayed.

118 Power analyses were originally done when the present study was launched at age 10, based on

119 CHQ-PF50 summary scores (Vederhus and others 2010). Applying post-hoc analyses, the study

120 had $80 \%$ power to detect group differences of approximately 5.5 points, providing a significance

121 level of 0.05 . Findings from that study suggested that stratification on gender would provide

122 important hypothesis-generating pilot data; hence, the present design despite loss of statistical

123 power. Group mean values are given with $95 \%$ confidence intervals to provide measures of

124 uncertainty.

125 Ethics 
126 The study was approved by the Regional Committee on Medical Research Ethics of the Western

127 Norway Regional Health Authority (file no. 99.2000), and was performed in accordance with the 128 Helsinki Declaration. Informed consent was obtained for each participating subjects and their 129 parents.

\section{Results}

\section{Participants}

All eligible EP-born subjects $(n=35)$ participated at 10 years of age. On average, 1.3 term-born children were approached to recruit a full 1:1 matched control group. Clinical and sociodemographic characteristics at 10 and 18 years of age are presented in Table S1.

At 18 years, 31 (89\%) of the EP and $29(83 \%)$ of the term-born controls participated (four EPborn females and four males and two females born at term declined). Twenty-three mothers and seven fathers completed the questionnaires in the EP-born group vs. 22 mothers, five fathers and one parent couple in the control group. There were one single parent and five divorced/separated couples in both the EP and term-born group.

\section{Development from 10 to 18 years of age as reported by parents}

Results from the mixed linear regression of the CHQ-PF50-scales are presented in Table 1 and illustrated in "Fig. 1". Parents of the EP-born subjects tended to give lower scores than parents of the term-born peers at both 10 and 18 years. Split by gender, the differences were smaller for girls than boys. For EP-born boys, the parents' scores tended to improve from 10 to 18 years on all scales relative to those of the term-born controls; however, significant only for self-esteem, 
general health and parental impact-time (group by age interaction). For the EP-born girls the score trajectories did not differ from those of the controls.

Results from the mixed linear regression of the CBCL-scales are presented in Table 2 and illustrated in "Fig. 2". Similarly to that of CHQ-PF50, the parents of the EP-born subjects tended to give their children poorer scores than the parents of the term-born controls on all scales at both ages, but the differences were largely greater for the boys. Relative to the controls the scores tended to improve from 10 to 18 years for the boys, although this relative improvement was significant only for the total problem, internalizing and anxious/depressed scales (group by age interaction). For the EP-born girls the score trajectories did not differ from those of the controls. Competence scores remained significantly poorer for both genders at 18 years.

\section{Factors influencing development of HRQoL from 10 to 18 years}

When adjusting for gender, ADHD/mild mental retardation, maternal education and CHQ-PF50scores at 10 years in the mixed linear regression model, higher CBCL total problem score at 10 years predicted poorer development of CHQ-PF50 scale-scores from 10 to 18 years. This effect was statistically significant for the scales role/social-emotional/behavioral, bodily pain, mental health, self-esteem, emotional impact on the parents and family cohesion (Table 3). The effects were similar for the subjects born EP and at term. However, the effect of gender was different in the EP vs. the term-born subjects, in that EP-born boys showed significantly greater improvement in the domains mental health and self-esteem while girls showed no such improvement.

\section{Self-reported CHQ and YSR at 18 years}

The EP-born and term-born adolescents scored themselves similarly on CHQ-CF87, and the scores were also similar after adjusting for gender, GSE, ADHD/mild mental retardation and 
maternal education in regression models (Table 4). Split by gender, EP-born females had lower scores on self-esteem in the unadjusted but not in the adjusted model. For the males, there were no group differences in the unadjusted analyses, but in the adjusted model males born EP scored better than males born at term on the scales role/social emotional and self-esteem (group by gender interaction).

On the YSR, the EP and term-born males scored themselves similarly while the EP-born females gave poorer scores than term-born females on the withdrawn and anxious/depressed scales (1.5; 95\% CI: -0.0 to $3.1 ; \mathrm{p}=0.05$ and $2.7 ; 95 \% \mathrm{CI}: 0.2$ to $5.1 ; \mathrm{p}=0.03$, respectively) and the social competence scale $(-1.6 ; 95 \% \mathrm{CI}:-2.7$ to $-0.5 ; \mathrm{p}=0.008)$. In the adjusted model, EP-born subjects reported significantly fewer externalizing problems than their term-born peers (Table 4).

GSE score was positively associated with most of the CHQ-CF87-scales and negatively associated with the internalizing, externalizing and total problem scale on the YSR in both EP and term-born adolescents (Table 4).

\section{Influence of neonatal variables in EP-born subjects at 18 years}

In the backward stepwise linear regression analysis, only number of days of mechanical ventilation remained a significant predictor of the three CBCL scales social, thought and attention; $\mathrm{b}=0.09 ; 95 \% \mathrm{CI}: 0.03$ to 0.15 (adjusted $\mathrm{R}^{2}=0.22$ ), $\mathrm{b}=0.06 ; 95 \% \mathrm{CI}: 0.03$ to 0.09 (adjusted $\mathrm{R}^{2}=0.29$ ), and $\mathrm{b}=0.16 ; 95 \% \mathrm{CI}: 0.07$ to 0.25 (adjusted $\mathrm{R}^{2}=0.28$ ), respectively. No significant associations were found with any of the CHQ-scales.

\section{Discussion}


To our knowledge, this is the first controlled study reporting longitudinal parent assessments of HRQoL and emotional and behavioral difficulties from mid-childhood to early adulthood in subjects born EP in the 1990s. At 10 years of age, boys born EP were assessed as having substantially more problems with emotion/behavior, competence and HRQoL than peers born at term, while at 18 these differences were considerably smaller. For the girls, differences were generally smaller and did not change much during puberty. Emotional and behavioral difficulties at 10 years of age were associated with less favorable development of HRQoL through puberty in both the EP and the term-born group. However, judged by self-reports at 18 years, HRQoL and emotional/behavioral issues were scored relatively similar in the EP and term-born groups, except that EP-born girls reported more withdrawal, anxiety and depression and lower social competence. GSE was associated with better HRQoL and less emotional and behavioral difficulties irrespective of group.

\section{Developmental trajectories}

Our longitudinal data obtained from the parents suggest that negative consequences of preterm birth on HRQoL and behavior tend to diminish over time for boys. A positive development of HRQoL corresponds with data presented in a review article, but in that paper it was discussed whether improvements reflected a shift from parent to self-report which is known to give different assessments (Zwicker and Harris 2008). Contrary to our findings a previous study of EP-born and term-born subjects born in 1977-82 reported that all participants perceived a small decrease in HRQoL from adolescence to young adulthood, but that was by self-reports (Saigal and others 2006). A decline in general health was reported also by children born with extremely low birth-weight in 1992-95 and their term-born controls from 8 to 14 years of age (Hack and others 2012). The difference in HRQoL and behavior trajectories between EP-born boys and girls observed in our study may be due to the fact that girls were assessed as having fewer difficulties 
212 at 10 years and therefore had less room for improvement. Also to be considered is that girls in

213 general, tend to have a less favorable development of HRQoL and mental health through puberty

214 than boys (Bongers and others 2003; Michel and others 2009). There were, however, still

215 differences in scores between EP and term-born subjects of both genders at 18 years. It is

216 therefore likely that some differences in HRQoL and behavior will remain towards young

217 adulthood. Regarding the significance of gender, studies of EP-born subjects have been

218 inconsistent in that more emotional/behavioral difficulties have been described for males at 17

219 years (Grunau and others 2004) as well as for females at 20 years (Hack and others 2004).

220 Internalizing symptoms in eight year old EP-born girls predicted persistent internalizing

221 symptoms at 20 years in a study by Hack et al. (Hack and others 2005), which is in accord with

222 our observation.

223 Normal behavior and HRQoL are important premises for social functioning, and the

224 improvements towards that of peers born at term at young adulthood are reassuring in terms of

225 the likelihood of living normal self-supportive lives. This notion is supported by a register-based

226 study of adults in Norway which, after excluding people on disability pensions, demonstrated that

227 level of education and chance of having a paid job only marginally decreased with degree of

228 prematurity (Moster and others 2008). However, these adults were born during 1967-83 when

229 few EP-born infants survived.

230 Inferior HRQoL has been reported in children and adolescents with behavioral problems (Klassen

231 and others 2004), also in children born EP (Saigal and others 2006; Verrips and others 2012). In

232 one study, internalizing behavior at eight years predicted poorer HRQoL at 13 years in children

233 born with very low birth-weight or very preterm, but not in the term-born control children (Wolke

234 and others 2013). In contrast, we found that emotional/behavioral difficulties at 10 years

235 predicted less improvement in HRQoL at young adulthood both for EP-born and term-born 
236 subjects, suggesting that the effect of behavior is a general phenomenon and not related to

237 prematurity per se.

238 Self-assessment at 18 years

239 The finding that EP and term-born individuals scored their HRQoL similarly is in agreement with

240 most reports on survivors of preterm birth (Hack and others 2007; Indredavik and others 2005;

241 Roberts and others 2013; Saigal and others 2006), but in contrast to some who report inferior

242 mental health and well-being (Lund and others 2012; Methusalemsdottir and others 2013; Saigal

243 and others 2007). Earlier reports on behavior are more inconsistent (Boyle and others 2011; Dahl

244 and others 2006; Grunau and others 2004; Hack and others 2004; Lund and others 2012; Saigal

245 and others 2003). Interestingly, the EP-born males reported their self-esteem to be better than the

246 term-born males, whereas the scores were opposite for the females. This gender difference was in

247 agreement with their parents' assessments. Others have also reported that self-esteem of EP-born

248 adolescents was comparable to that of controls, but not the gender difference observed in the

249 present study (Roberts and others 2013; Saigal and others 2002).

250 Contrary to a previous study (Verrips and others 2012), we found that confidence in the ability to

251 achieve goals (GSE score) was positively associated with self-reported HRQoL and emotional

252 health irrespective of group. This finding may be important because GSE is a trait that can be

253 modified and strengthened by interventions (Axelsson and others 2012). Moreover, it was

254 encouraging that EP-born subjects reported fairly similar levels of leisure time activities and

255 social interaction as term-born peers, which is contrary to previous reports of disadvantages in

256 sports and friendship (Dahan-Oliel and others 2012; Hallin and Stjernqvist 2010). Bullying in

257 preterm born adolescents have been reported (Grindvik and others 2009), but was not found in

258 the present study. 
Little is known concerning the significance of neonatal exposures on later HRQoL and emotional issues. Neonatal morphine exposure and neonatal procedural pain predicted internalizing behavior in 7-year old very preterm born children in one study (Ranger and others 2013). We found an association between duration of mechanical ventilation and emotional problems at 18 years. In the present we have previously reported on a negative association between neonatal corticosteroid treatment and social functioning at ten years (Vederhus and others 2010), but no such association was found at 18 years.

\section{Strengths and weaknesses}

The major strengths of this study were the population-based and controlled design and high follow-up rate, and that the assessments were made by the same research team on both occasions. No subjects in this birth-cohort had major impairments, and there were no exclusions for medical reasons, thus the results may not be generalized to those with severe neurodevelopmental impairments. The use of both parent- and self-reports facilitated better understanding of developmental patterns.

The limitation of this study was primarily a relatively low number of participants, and positive as well as negative findings must therefore be cautiously interpreted. HRQoL research is characterized by a high number of endpoints, challenging a priori power calculations, which was further complicated in this study by partly unknown distributions in preterm born populations, and by the longitudinal perspective. Although debatable (Fayers and Machin 2007), a post hoc power analysis was reported at age 10 (Vederhus and others 2010), indicating a between-group detection limit of 5.5 for CHQ-PF50 summary scores, a figure considered adequate by the creator (Landgraf and others 1999). Stratifying by gender reduced the size of the groups, and therefore also statistical power. Nevertheless, this was considered important and necessary, given the 
282 findings at age 10 and the known influence from gender during puberty on the issues under study.

283 Given the relatively small sample size, the present findings should primarily be considered

284 hypothesis-generating pilot data and an incitement for future research, preferably in larger

285 population samples. To a large extent we have given $95 \%$ confidence intervals for calculated

286 group mean values, in order to indicate the reliability of the estimates.

\section{Conclusion}

288 For EP-born boys, parents' assessments of HRQoL, emotion and behavior improved towards that of term-born controls from 10 to 18 years of age, and for both genders and for children born EP and at term emotional/behavioral difficulties at 10 predicted less improvement in HRQoL at age 18. As there were still some important group differences at age 18 , we are concerned that our findings may herald difficulties in a complex and demanding adult life. The present pilot data imply that gender and a longitudinal perspective are important aspects when addressing HRQoL and behavioral issues after preterm birth, and that these issues should be considered in clinical work as well as in future and preferably larger studies. 


\section{Acknowledgements}

297 We sincerely thank the children and their parents who gave of their time to take part in this 298 follow-up study. 


\section{References}

Axelsson M, Lotvall J, Cliffordson C, Lundgren J, Brink E. 2012. Self-efficacy and adherence as mediating factors between personality traits and health-related quality of life. Qual Life Res.

Aylward GP. 2005. Neurodevelopmental outcomes of infants born prematurely. J Dev Behav Pediatr 26(6):42740.

Berbis J, Einaudi MA, Simeoni MC, Brevaut-Malaty V, Auquier P, d'Ercole C, Gire C. 2012. Quality of life of early school-age French children born preterm: a cohort study. Eur J Obstet Gynecol Reprod Biol 162(1):3844.

Bongers IL, Koot HM, van der Ende J, Verhulst FC. 2003. The normative development of child and adolescent problem behavior. J Abnorm Psychol 112(2):179-92.

Boyle MH, Miskovic V, Van LR, Duncan L, Schmidt LA, Hoult L, Paneth N, Saigal S. 2011. Psychopathology in young adults born at extremely low birth weight. Psychol Med 41(8):1763-74.

Dahan-Oliel N, Mazer B, Majnemer A. 2012. Preterm birth and leisure participation: a synthesis of the literature. Res Dev Disabil 33(4):1211-20.

Dahl LB, Kaaresen PI, Tunby J, Handegard BH, Kvernmo S, Ronning JA. 2006. Emotional, behavioral, social, and academic outcomes in adolescents born with very low birth weight. Pediatrics 118:e449-e459.

Doyle LW, Anderson PJ. 2010. Adult outcome of extremely preterm infants. Pediatrics 126(2):342-51.

Fayers PM, Machin D. 2007. Quality of life The assessment, analysis and interpretation of patient-reported outcomes. Second edition. West Sussex: John Wiley \& Sons Ltd.

Grindvik AS, Hodol JS, Vik T, Evensen KA, Skranes J, Brubakk AM, Indredavik MS. 2009. Bullying among adolescents with very low birth weight. Acta Paediatr 98(6):1049-51.

Grunau RE, Whitfield MF, Fay TB. 2004. Psychosocial and academic characteristics of extremely low birth weight ( $<$ or $=800 \mathrm{~g}$ ) adolescents who are free of major impairment compared with term-born control subjects. Pediatrics 114:e725-e732.

Hack M. 2009. Adult outcomes of preterm children. J Dev Behav Pediatr 30(5):460-70.

Hack M, Cartar L, Schluchter M, Klein N, Forrest CB. 2007. Self-perceived health, functioning and wellbeing of very low birth weight infants at age 20 years. $J$ Pediatr 151(6):635-41, 641.

Hack M, Schluchter M, Forrest CB, Taylor HG, Drotar D, Holmbeck G, Youngstrom E, Margevicius S, Andreias L. 2012. Self-reported adolescent health status of extremely low birth weight children born 19921995. Pediatrics 130(1):46-53.

Hack M, Youngstrom EA, Cartar L, Schluchter M, Taylor GH, Flannery DJ, Klein N, Borawski E. 2005. Predictors of internalizing symptoms among very low birth weight young women. $J$ Dev Behav Pediatr 26(2):93-104.

Hack M, Youngstrom EA, Cartar L, Schluchter M, Taylor HG, Flannery D, Klein N, Borawski E. 2004. Behavioral outcomes and evidence of psychopathology among very low birth weight infants at age 20 years. Pediatrics 114(4):932-40.

Hallin AL, Stjernqvist K. 2010. Follow-up of adolescents born extremely preterm: Self-perceived mental health, social, and relational outcomes. Acta Paediatr. 
Indredavik MS, Vik T, Heyerdahl S, Romundstad P, Brubakk AM. 2005. Low-birthweight adolescents: quality of life and parent-child relations. Acta Paediatr 94:1295-302.

Johnson S, Wolke D. 2013. Behavioural outcomes and psychopathology during adolescence. Early Hum Dev.

Klassen AF, Miller A, Fine S. 2004. Health-related quality of life in children and adolescents who have a diagnosis of attention-deficit/hyperactivity disorder. Pediatrics 114(5):e541-e547.

Landgraf JM, Abetz L, Ware JE. 1999. The CHQ User's Manual. Second printing. Boston, MA: HealthAct. 11 p.

Lund LK, Vik T, Lydersen S, Lohaugen GC, Skranes J, Brubakk AM, Indredavik MS. 2012. Mental health, quality of life and social relations in young adults born with low birth weight. Health Qual Life Outcomes 10:146.

Markestad T, Kaaresen PI, Ronnestad A, Reigstad H, Lossius K, Medbo S, Zanussi G, Engelund IE, Skjaerven R, Irgens LM. 2005. Early death, morbidity, and need of treatment among extremely premature infants. Pediatrics 115:1289-98.

Methusalemsdottir HF, Egilson SO, Guethmundsdottir R, Valdimarsdottir UA, Georgsdottir I. 2013. Quality of life of adolescents born with extremely low birth weight. Acta Paediatr.

Michel G, Bisegger C, Fuhr DC, Abel T. 2009. Age and gender differences in health-related quality of life of children and adolescents in Europe: a multilevel analysis. Qual Life Res 18(9):1147-57.

Moster D, Lie RT, Markestad T. 2008. Long-term medical and social consequences of preterm birth. $N$ Engl $J$ Med 359:262-73.

Novik TS. 1999. Validity of the Child Behaviour Checklist in a Norwegian sample. Eur Child Adolesc Psychiatry 8(4):247-54.

Ranger M, Synnes AR, Vinall J, Grunau RE. 2013. Internalizing behaviours in school-age children born very preterm are predicted by neonatal pain and morphine exposure. Eur J Pain.

Roberts G, Burnett AC, Lee KJ, Cheong J, Wood SJ, Anderson PJ, Doyle LW. 2013. Quality of Life at Age 18 Years after Extremely Preterm Birth in the Post-Surfactant Era. $J$ Pediatr.

Roysamb, E., Schwarzer, R., and jer. 1999. Norwegian Version of the General Perceived Self-Efficacy Scale. Available at http://userpage.fu-berlin.de/ health/norway.htm.

Saigal S. 2013. Quality of life of former premature infants during adolescence and beyond. Early Hum Dev 89(4):209-13.

Saigal S, Lambert M, Russ C, Hoult L. 2002. Self-esteem of adolescents who were born prematurely. Pediatrics 109(3):429-33.

Saigal S, Pinelli J, Hoult L, Kim MM, Boyle M. 2003. Psychopathology and social competencies of adolescents who were extremely low birth weight. Pediatrics 111(5 Pt 1):969-75.

Saigal S, Stoskopf B, Boyle M, Paneth N, Pinelli J, Streiner D, Goddeeris J. 2007. Comparison of current health, functional limitations, and health care use of young adults who were born with extremely low birth weight and normal birth weight. Pediatrics 119(3):e562-e573.

Saigal S, Stoskopf B, Pinelli J, Streiner D, Hoult L, Paneth N, Goddeeris J. 2006. Self-perceived health-related quality of life of former extremely low birth weight infants at young adulthood. Pediatrics 118(3):1140-8. 
Schwarzer R, Bassler J, Kwiatek P, Schroder K, Zhang JAX. 1997. The assessment of optimistic self-beliefs: Comparison of the German, Spanish, and Chinese versions of the general self-efficacy scale. Applied Psychology-An International Review-Psychologie Appliquee-Revue Internationale 46(1):69-88.

Selvaag AM, Ruperto N, Asplin L, Rygg M, Landgraf JM, Forre O, Flato B. 2001. The Norwegian version of the Childhood Health Assessment Questionnaire (CHAQ) and the Child Health Questionnaire (CHQ). Clin Exp Rheumatol 19:S116-S120.

Stahlmann N, Rapp M, Herting E, Thyen U. 2009. Outcome of extremely premature infants at early school age: health-related quality of life and neurosensory, cognitive, and behavioral outcomes in a population-based sample in northern Germany. Neuropediatrics 40(3):112-9.

The Nord-Trøndelag Health Study. 2012. Available at http://www.ntnu.edu/hunt/data (accessed 6-3-2012).

Vederhus BJ, Markestad T, Eide GE, Graue M, Halvorsen T. 2010. Health related quality of life after extremely preterm birth: a matched controlled cohort study. Health Qual Life Outcomes 8:53.

Verrips G, Brouwer L, Vogels T, Taal E, Drossaert C, Feeny D, Verheijden M, Verloove-Vanhorick P. 2012. Long term follow-up of health-related quality of life in young adults born very preterm or with a very low birth weight. Health Qual Life Outcomes 10:49.

Wilson-Costello D, Friedman H, Minich N, Fanaroff AA, Hack M. 2005. Improved survival rates with increased neurodevelopmental disability for extremely low birth weight infants in the 1990s. Pediatrics 115(4):997-1003.

Wolke D, Chernova J, Eryigit-Madzwamuse S, Samara M, Zwierzynska K, Petrou S. 2013. Self and parent perspectives on health-related quality of life of adolescents born very preterm. $J$ Pediatr 163(4):1020-6.

Zwicker JG, Harris SR. 2008. Quality of life of formerly preterm and very low birth weight infants from preschool age to adulthood: a systematic review. Pediatrics 121:e366-e376. 


\section{Table $\mathbf{1}$ (on next page)}

Parent-reported Child Health Questionnaire at 10 and 18 years of age in EP-and termborn children 
Table 1. Parent-reported Child Health Questionnaire at 10 and 18 years in EP- and term-born children

\begin{tabular}{|c|c|c|c|c|c|c|}
\hline \multicolumn{4}{|c|}{ Boys } & \multicolumn{3}{|c|}{ Girls } \\
\hline Age at follow-up: & $\begin{array}{l}10 \text { years } \\
(\mathrm{n}=26)\end{array}$ & $\begin{array}{l}18 \text { years } \\
(\mathrm{n}=22)\end{array}$ & & $\begin{array}{c}10 \text { years } \\
(\mathrm{n}=44)\end{array}$ & $\begin{array}{l}18 \text { years } \\
\left(\mathrm{n}=38^{\mathrm{a}}\right)\end{array}$ & \\
\hline CHQ-PF50 scales & $\begin{array}{l}\text { Estimated mean } \\
\text { difference (95\% CI) } \\
\text { EP vs. term-born }\end{array}$ & $\begin{array}{l}\text { Estimated mean } \\
\text { difference (95\% CI) } \\
\text { EP vs. term-born }\end{array}$ & $\begin{array}{c}\text { Tests of } \\
\text { interaction } \\
\text { group by age } \\
\text { p-values }{ }^{\mathrm{b}}\end{array}$ & $\begin{array}{l}\text { Estimated mean } \\
\text { difference }(95 \% \mathrm{CI}) \\
\text { EP vs. term-born }\end{array}$ & $\begin{array}{l}\text { Estimated mean } \\
\text { difference }(95 \% \mathrm{CI}) \\
\text { EP vs. term-born }\end{array}$ & $\begin{array}{c}\text { Tests of } \\
\text { interaction } \\
\text { group by age } \\
\text { p-values } \\
\end{array}$ \\
\hline Physical functioning & $-7.9(-15.7,-0.2)$ & $-2.3(-10.9,6.3)$ & 0.33 & $-2.3(-6.3,1.8)$ & $-5.4(-9.8,-0,9)$ & 0.31 \\
\hline $\begin{array}{l}\text { Role/social - } \\
\text { emotional/behavioral }\end{array}$ & $-23,9(-42,2,-5.7)$ & $-8.4(-28.5,11.8)$ & 0.25 & $-4.0(-11.5,3.4)$ & $-3.8(-11.9,4.3)$ & 0.96 \\
\hline Role/social - physical & $-10.3(-19.8,-0.7)$ & $-4.4(-15.0,6.2)$ & 0.56 & $-0.8(-7.6,6.1)$ & $-1.1(-8.6,6.4)$ & 0.95 \\
\hline Bodily pain & $-8.5(-22.6,5.7)$ & $-6.8^{\mathrm{c}}(-23.1,9.5)$ & 0.96 & $-2.7(-15.2,9.8)$ & $-3.9^{c}(-17.8,9.9)$ & 0.89 \\
\hline Behavior & $-24.2(-37.7,-10.6)$ & $-7.8(-22.7,7.2)$ & 0.11 & $-6.4(-13.4,0.6)$ & $-4.8(-12.5,2.9)$ & 0.76 \\
\hline Mental health & $-8.8(-18.3,0.6)$ & $-0.5(-11.0,9.9)$ & 0.24 & $-3.9(-8.8,1.1)$ & $-7.0(-12.5,-1.6)$ & 0.39 \\
\hline Self-esteem & $-8.3(-19.8,3.1)$ & $11.3(-1.6,24.1)$ & 0.03 & $-5.5(-13.6,2.6)$ & $-7.5(-16.4,1.3)$ & 0.74 \\
\hline General health & $-27.8(-39.2,-16.5)$ & $-7.5(-20.2,5.2)$ & 0.02 & $-17.2(-26.3,-8.2)$ & $-11.2(-21.2,-1.3)$ & 0.38 \\
\hline Parental impact -emotional & $-35.3(-52.9,-17.6)$ & $-11.7(-31.3,7.8)$ & 0.08 & $-12.5(-20.3,-4.7)$ & $-8.0(-16.6,0.6)$ & 0.44 \\
\hline Parental impact - time & $-21.4(-31.9,-10.8)$ & $-3.8(-15.6,8.1)$ & 0.03 & $-7.1(-12.3,-1.8)$ & $-2.1 \quad(-7.8,3.7)$ & 0.21 \\
\hline Family activity & $-23.1(-38.6,-7.5)$ & $-2.8(-20.2,14.6)$ & 0.09 & $-6.7(-14.6,1.2)$ & $-5.5(-14.2,3.2)$ & 0.84 \\
\hline Family cohesion & $-2.3(-16.9,12.3)$ & $5.1(-11.3,21.5)$ & 0.50 & $-3.2(-13.1,6.8)$ & $-0.6(-11.5,10.3)$ & 0.73 \\
\hline
\end{tabular}

$\mathrm{EP}=$ extremely preterm. Higher scores in each of the CHQ scales reflect better outcome (range $0-100$ ).

a) One report was missing

b) From mixed linear model: interaction-term testing if development from 10 to 18 years differed in the EP vs. the term-born group

c) One missing 
Table 2 (on next page)

Parent-reported Child Behavior Checklist at 10 and 18 years in EP- and term-born children. 
Table 2. Parent-reported Child Behavior Checklist at 10 and 18 years in EP- and term-born children

\begin{tabular}{|c|c|c|c|c|c|c|}
\hline \multicolumn{4}{|c|}{ Boys } & \multicolumn{3}{|c|}{ Girls } \\
\hline Age at follow-up: & $\begin{array}{l}10 \text { years } \\
(n=26)\end{array}$ & $\begin{array}{l}18 \text { years } \\
(\mathrm{n}=22)\end{array}$ & & $\begin{array}{c}10 \text { years } \\
\left(\mathrm{n}=44^{\mathrm{a}}\right)\end{array}$ & $\begin{array}{c}18 \text { years } \\
\left(\mathrm{n}=38^{\mathrm{b}}\right)\end{array}$ & \\
\hline CBCL scales & $\begin{array}{c}\text { Estimated mean } \\
\text { difference }(95 \% \mathrm{CI}) \\
\text { EP- vs. term-born }\end{array}$ & $\begin{array}{c}\text { Estimated mean } \\
\text { difference }(95 \% \mathrm{CI}) \\
\text { EP- vs. term-born }\end{array}$ & $\begin{array}{c}\text { Tests of } \\
\text { interaction } \\
\text { group by age } \\
\text { p-values }{ }^{\mathrm{c}} \\
\end{array}$ & $\begin{array}{c}\text { Estimated mean } \\
\text { difference }(95 \% \mathrm{CI}) \\
\text { EP- vs. term-born }\end{array}$ & $\begin{array}{c}\text { Estimated mean } \\
\text { difference }(95 \% \text { CI) } \\
\text { EP- vs. term-born }\end{array}$ & $\begin{array}{c}\text { Tests of } \\
\text { interaction } \\
\text { group by age } \\
\text { p-values } \\
\end{array}$ \\
\hline Total problem & $37.3(20.7,54.0)$ & $9.8(-8.9,28.5)$ & 0.03 & $9.6(2.4,16.8)$ & $9.8(2.1,17.4)$ & 0.97 \\
\hline Internalizing & $10.3(5.3,15.3)$ & $2.1(-3.5,7.7)$ & 0.03 & $2.6(-0.7,5.8)$ & $5.6(2.2,9.1)$ & 0.20 \\
\hline Externalizing & $11.1(4.9,17.3)$ & $2.2(-4.8,9.2)$ & 0.06 & $2.3(-0.7,5.2)$ & $1.8(-1.4,5.0)$ & 0.82 \\
\hline Withdrawn & $2.8(1.1,4.5)$ & $0.3(-1.6,2.2)$ & 0.06 & $1.3(0.1,2.5)$ & $2.4(1.2,3.7)$ & 0.21 \\
\hline Somatic complaints & $1.8(0.4,3.2)$ & $0.6(-1.0,2.2)$ & 0.28 & $0.04(-1.3,1.4)$ & $0.1(-1.4,1.6)$ & 0.96 \\
\hline Anxious/depressed & $6.2(3.1,9.2)$ & $1.0(-2.4,4.4)$ & 0.03 & $1.3(-0.3,3.0)$ & $3.4(1.7,5.2)$ & 0.08 \\
\hline Social problems & $3.9(2.3,5.5)$ & $1.7(-0.1,3.5)$ & 0.07 & $2.6(1.6,3.6)$ & $1.3(0.2,2.4)$ & 0.09 \\
\hline Thought problems & $2.2(1.0,3.3)$ & $0.7(-0.7,2.0)$ & 0.09 & $0.2(-0.1,0.5)$ & $0.2(-0.2,0.5)$ & 0.75 \\
\hline Attention problems & $6.2(3.7,8.7)$ & $2.8(-0.03,5.6)$ & 0.07 & $2.2(0.9,3.4)$ & $1.2(-0.2,2.6)$ & 0.30 \\
\hline Delinquent behavior & $2.2(0.8,3.7)$ & $0.2(-1.4,1.8)$ & 0.07 & $-0.02(-0.8,0.8)$ & $0.1(-0.7,1.0)$ & 0.78 \\
\hline Aggressive behavior & $8.8(3.8,13.8)$ & $2.0(-3.6,7.7)$ & 0.08 & $2.3(-0.2,4.8)$ & $1.6(-1.0,4.3)$ & 0.73 \\
\hline Total competence & $-3.2^{\mathrm{d}}(-6.1,-0.4)$ & $-3.7^{\mathrm{e}}(-7.1,-0.2)$ & 0.84 & $-3.8^{f}(-5.8,-1.7)$ & $-5.0^{\mathrm{e}}(-7.3,-2.8)$ & 0.39 \\
\hline Activities & $-0.5^{\mathrm{g}}(-1.7,0.6)$ & $-0.8^{\mathrm{g}}(-2.1,0.5)$ & 0.78 & $-1.4^{\mathrm{g}}(-2.4,-0.3)$ & $-1.4^{\mathrm{g}}(-2.5,-0.3)$ & 0.93 \\
\hline Social competence & $-1.0^{\mathrm{d}}(-2.4,0.5)$ & $-1.2(-2.8,0.3)$ & 0.81 & $-1.6^{\mathrm{g}}(-2.7,-0.5)$ & $-2.0^{\mathrm{d}}(-3.2,-0.7)$ & 0.66 \\
\hline School competence & $-2.0(-2.9,-1.0)$ & $-2.0^{\mathrm{h}}(-3.2,-0.8)$ & 0.96 & $-1.0^{\mathrm{g}}(-1.6,-0.4)$ & $-0.6^{\mathrm{f}}(-1.3,0.0)$ & 0.38 \\
\hline
\end{tabular}

$\mathrm{EP}=$ extremely preterm. Higher score on each of the CBCL scales reflects more problems or better competencies.

a) Two reports were missing

b) One report was missing

c) Mixed linear model. Interaction-terms assessing if the differences between the EP and the matched term-born control groups were different at ten and 18 years of age

d) Two missing e) Five missing f) Three missing g) One missing h) Four missing 
Table 3(on next page)

Predictors for changes in parent reported health-related quality of life from 10 to 18 years of age for EP- and term-born children 


\section{PeerJ Reviewing Manuscript}

Table 3. Predictors for changes in parent reported health-related quality of life from 10 to 18 years of age for EP- and term-born children

\begin{tabular}{|l|l|c|c|}
\hline Response variable & \multicolumn{2}{|c|}{ Explanatory variables $^{\text {a }}$} \\
\hline $\begin{array}{l}\text { CHQ-PF50 scale changes } \\
\text { (score range 0-100) }\end{array}$ & Gender $^{\text {b }}$ & $\begin{array}{c}\text { EP- vs. term-born } \\
(\mathrm{n}=57) \\
\text { b (95\%CI) }\end{array}$ & $\begin{array}{c}\text { CBCL total problem score } \\
\mathbf{a t ~ 1 0 ~ y e a r s ~}^{\mathbf{c}} \\
\text { b (95\% CI) }\end{array}$ \\
\hline Physical functioning & & $-2.0(-6.7,2.7)$ & $-0.1(-0.2,0.1)$ \\
\hline Role/social - emotional/behavioral & & $0.8(-9.2,10.9)$ & $-0.7(-1.0,-0.3)^{* * *}$ \\
\hline Role/social - physical & & $0.9(-6.0,7.8)$ & $-0.1(-0.3,0.1)$ \\
\hline Bodily pain ${ }^{\text {d }}$ & & $7.1(-4.1,18.3)$ & $-0.4(-0.7,-0.02)^{*}$ \\
\hline Behavior & & $1.9(-5.9,9.6)$ & $-0.2(-0.5,0.03)$ \\
\hline Mental health & Boys & $8.5^{\mathrm{e}}(-1.1,18.2)$ & $-0.3(-0.5,-0.04)^{*}$ \\
\hline Self-esteem & Girls & $-4.8(-10.8,1.2)$ & $-0.3(-0.5,-0.1)^{* *}$ \\
\hline General health & Boys & $19.3^{\mathrm{f}}(8.9,29.6)$ & $-0.03(-0.2,0.2)$ \\
\hline Parental impact - emotional & Girls & $-5.0(-11.6,1.5)$ & $-0.3(-0.6,-0.1)^{*}$ \\
\hline Parental impact - time & & $-2.7(-10.0,4.4)$ & $-0.1(-0.3,0.01)$ \\
\hline Family activity & & $1.5(-6.8,9.8)$ & $-0.2(-0.5,0.1)$ \\
\hline Family cohesion & & $0.9(-2.9,4.8)$ & $-0.4(-0.6,-0.1)^{*}$ \\
\hline
\end{tabular}

$\mathrm{EP}=$ extremely preterm, $\mathrm{CHQ}=$ Child Health Questionnaire-Parent Form50

a) Mixed linear regression model adjusted for CHQ-scores at 10 years, gender, maternal education at 10 years and attention deficit hyperactivity disorder/mild mental retardation $(\mathrm{n}=5)$.

P-values given as $* \leq 0.05 ; * * \leq 0.01 ; * * * \leq 0.001$, positive $\mathrm{b}$ indicates improved outcome.

b) Estimates are given specifically for boys and girls when there was a significant interaction group by gender.

c) Child Behavior Checklist - total problem score: negative association of total problem score indicates that high level of problems at 10 years of age predicts less improvement in CHQ-scores to 18 years.

d) Two missing

e) Interaction $p$-value $=0.017$

f) Interaction p-value $<0.001$ 


\section{Table 4(on next page)}

Self-reports at 18 years of age in adolescents born EP and at term 
Table 4. Self-reports at 18 years of age in adolescents born EP and at term

\begin{tabular}{|c|c|c|c|c|c|c|c|}
\hline & \multicolumn{4}{|c|}{ Unadjusted results } & \multicolumn{3}{|c|}{ Adjusted results $^{\mathrm{a}}$} \\
\hline $\begin{array}{l}\text { Response variable } \\
\text { CHQ-CF87 (range 0-100) }\end{array}$ & $\begin{array}{c}\text { EP-born } \\
(\mathrm{n}=31) \\
\text { mean (SE) }\end{array}$ & $\begin{array}{l}\text { Term-born } \\
(\mathrm{n}=29) \\
\text { mean (SE) }\end{array}$ & $\begin{array}{c}\text { EP- vs. term-born } \\
\text { estimated mean } \\
\text { differences }(95 \% \mathrm{CI})\end{array}$ & P-value & $\begin{array}{c}\text { EP- vs. term-born } \\
\text { b }(95 \% \mathrm{CI}) \\
\end{array}$ & $\begin{array}{l}\text { GSE score } \\
\text { b (95\% CI) }\end{array}$ & $\begin{array}{l}\text { Interaction term } \\
\text { group by gender } \\
\text { EP- vs. term-born } \\
\text { b }(95 \% \mathrm{CI}) \\
\end{array}$ \\
\hline Physical functioning & $93.7(2.9)$ & $98.5(0.6)$ & $-4.4(-9.0,0.2)$ & 0.06 & $-0.4(-5.4,4.7)$ & $5,4(1.3,9.6)^{*}$ & \\
\hline Role/social-emotional & $88.9(3.9)$ & $92.7(2.7)$ & $-3.9(-14.2,6.3)$ & 0.44 & & $13.6(6.1,21.1)^{* *}$ & $\begin{array}{l}\text { Boys: } 17.9(1.8,34.0)^{\mathrm{b}} \\
\text { Girls: }-1.7(-12.9,9.5) \\
\end{array}$ \\
\hline Role/social-behavioral & $95.0(2.8)$ & $99.2(0.5)$ & $-6.7(-16.4,2.9)$ & 0.16 & $2.0(-2.8,6.7)$ & $5.2(0.6,9.8)^{*}$ & \\
\hline Role/social-physical & $94.6(2.9)$ & $100.0(0.0)$ & $-5.4(-11.6,0.8)$ & 0.09 & $-0.1(-6.4,6.3)$ & $8.7(3.9,13.6)^{* *}$ & \\
\hline Bodily pain & $74.2(4.4)$ & $76.6(4.2)$ & $-2.1(-13.8,9.6)$ & 0.71 & $5.4(-6.6,17.4)$ & $-0.4(-10.8,10.0)$ & \\
\hline Behavior & $76.2(3.0)$ & $78.2(1.9)$ & $-1.9(-9.1,5.3)$ & 0.59 & $4.6(-2.6,11.8)$ & $9.9(3.9,15.8)^{* *}$ & \\
\hline Mental health & $72.9(3.2)$ & $75.1(2.1)$ & $-2.1(-10.1,5.8)$ & 0.59 & $2.5(-5.9,10.9)$ & $10.6(4.1,17.1)^{* *}$ & \\
\hline Self-esteem & $69.7(2.9)^{d}$ & $75.4(2.6)$ & $-6.1(-14.4,2.3)$ & 0.15 & & $15.1(9.4,20.9)^{* * *}$ & $\begin{array}{c}\text { Boys: } 14.2(3.4,25)^{\mathrm{c}} \\
\text { Girls: }-5.2(-12.7,2.2)\end{array}$ \\
\hline General health & $70.4(3.3)$ & $73.7(3.1)$ & $-3.0(-11.6,5.6)$ & 0.49 & $3.7(-5.9,13.3)$ & $11.6(3.8,19.5)^{* *}$ & \\
\hline Family activity & $88.0(3.3)$ & $91.4(2.5)$ & $-3.8(-13.1,5.5)$ & 0.40 & $1.0(-8.6,10.6)$ & $3.4(-3.8,10.7)$ & \\
\hline Family cohesion & $74.5(4.9)$ & $74.5(4.7)$ & $0.1(-13.9,14.0)$ & 0.99 & $7.6(-7.5,22.7)$ & $15.1(2.7,27.5)^{*}$ & \\
\hline \multicolumn{8}{|l|}{ YSR: } \\
\hline $\begin{array}{l}\text { Total problems } \\
\text { (range } 0-210)\end{array}$ & $33.0(5.2)$ & $29.1(3.1)$ & $3.7(-8.7,16.1)$ & 0.54 & $-9.9(-21.6,1.9)$ & $-20.7(-30.3,-11.1)^{* * *}$ & \\
\hline $\begin{array}{l}\text { Internalizing } \\
\text { (range } 0-62 \text { ) }\end{array}$ & $10.2(2.0)$ & $8.2(1.2)$ & $1.9(-2.8,6.6)$ & 0.41 & $-2.9(-7.4,1.5)$ & $-9.4(-12.8,-6.0)^{* * *}$ & \\
\hline $\begin{array}{l}\text { Externalizing } \\
\text { (range 0-64) }\end{array}$ & $8.4(1.3)$ & $9.8(1.0)$ & $-1.4(-4.7,1.9)$ & 0.39 & $-3.9(-7.4,-0.5)^{*}$ & $-3.3(-6.1,-0.4)^{*}$ & \\
\hline
\end{tabular}

$\mathrm{EP}=$ extremely preterm, $\mathrm{CHQ}=$ Child Health Questionnaire-Child Form87, YSR $=$ Youth Self-Report, GSE $=$ General Self-Efficacy (score range 1-4). Higher scores reflect better outcome on the CHQ, but more problems on the YSR.

a) Mixed linear model adjusted for gender, maternal education at 10 years of age, and attention deficit hyperactivity disorder/mild mental retardation. If interaction term group by gender was not significant $(\mathrm{p}>0.05)$ model without is reported. P-values given as $* \mathrm{p}<0.05,{ }^{* *} \mathrm{p}<0.01 * * * \mathrm{p}<0.001$

$\mathrm{b}$-c) Test of interaction assessing if differences between boys and girls were different in the EP and the term-born group; $p=0.040$ and $p=0.003$, respectively.

d) Split by gender, EP female 66.6 vs. term-born female 78.8, p-value $=0.009$ 
1

Parent-reported changes on the Child Health Questionnaire-scales from 10 to 18 years

Displayed for extremely preterm- and matched term-born control subjects split by gender: increasing scores imply improvements 

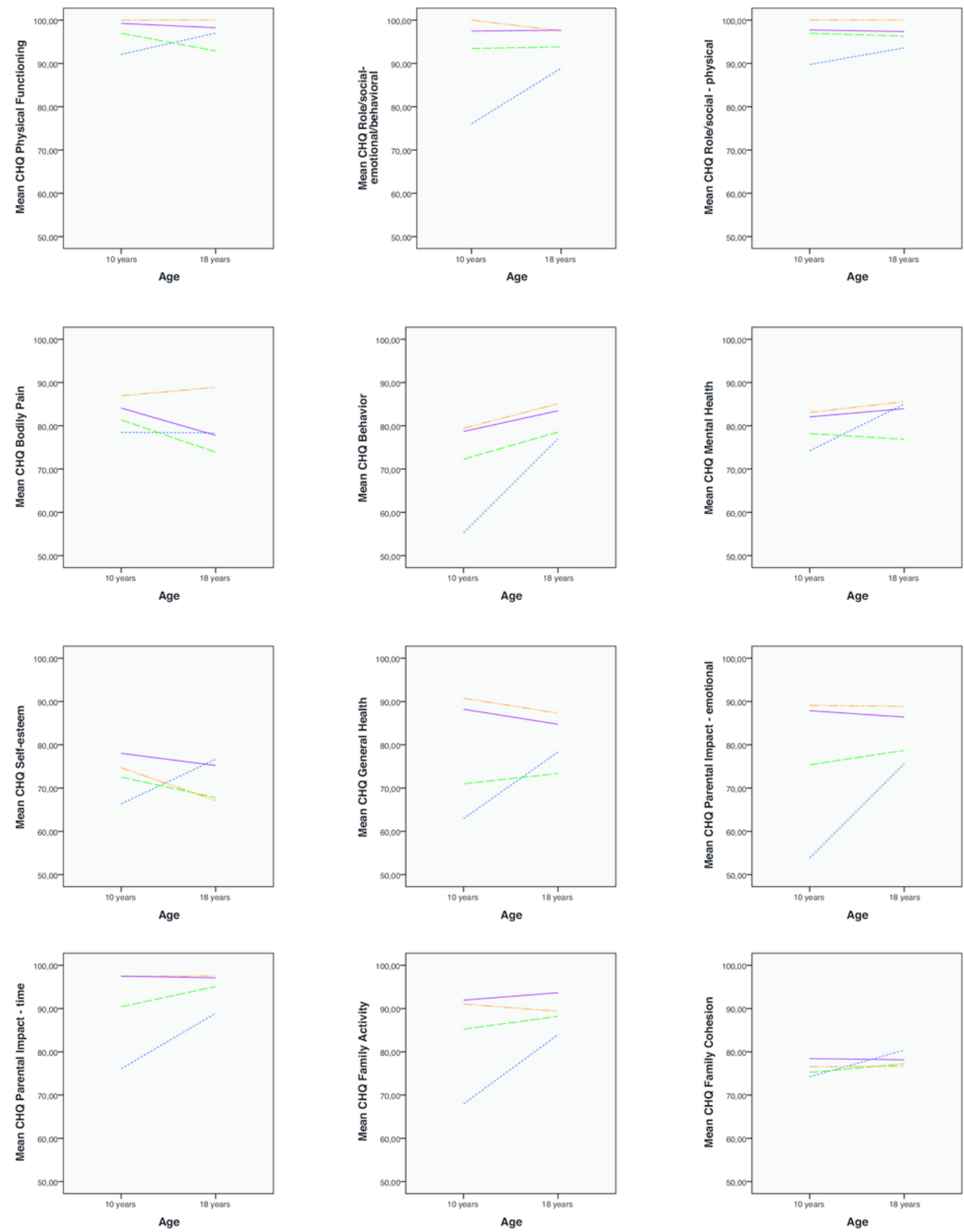

mwn $=$ Preterm boy

$=$ Preterm girl

=n! Term boy

Term girl 
2

Parent-reported changes on the Child Behavior Checklist-scales from 10 to 18 years

Displayed for extremely preterm- and matched term-born control subjects split by gender: decreasing scores imply improvements 

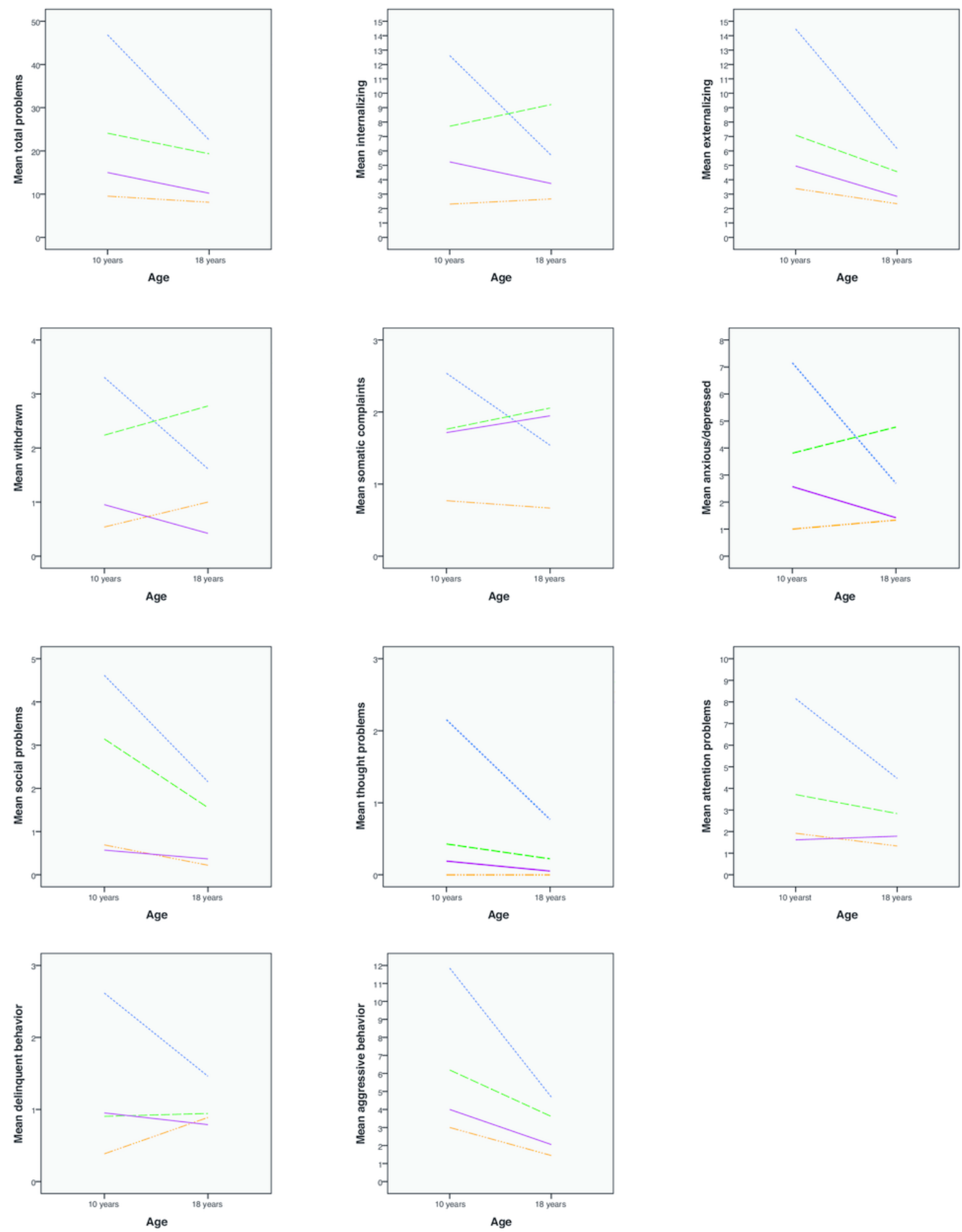

$m= \pm n$ Preterm boy

Preterm girl

- III Term boy

Term girl 